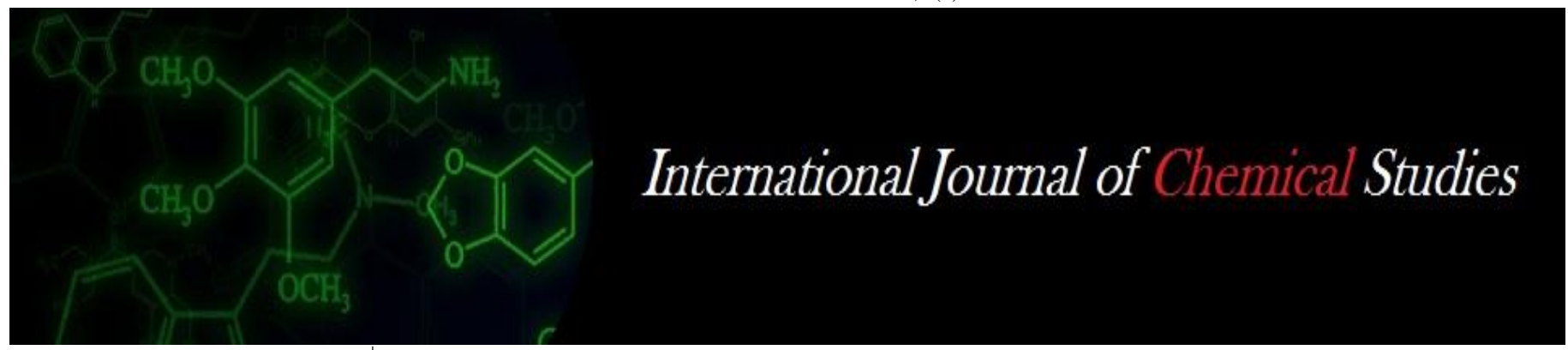

P-ISSN: 2349-8528

E-ISSN: 2321-4902

www.chemijournal.com

IJCS 2020; 8(3): 1991-1994

(C) 2020 IJCS

Received: 22-03-2020

Accepted: 24-04-2020

Janani P

ICAR- Central Potato Research

Station, Shillong, Meghalaya,

India

\section{Adiga JD}

ICAR-Directorate of Cashew Research, Puttur, Karnataka, India

Corresponding Author:

Janani P

ICAR- Central Potato Research

Station, Shillong, Meghalaya,

India

\section{Studies on effect of rootstocks on root distribution pattern of cashew}

\section{Janani $P$ and Adiga JD}

DOI: https://doi.org/10.22271/chemi.2020.v8.i3ab.9499

\begin{abstract}
The present investigation on the root distribution pattern of cashew rootstocks was carried out at ICARDirectorate of Cashew Research (DCR), Experimental Station, Santhigodu, Karnataka. The study aimed to understand the root distribution of two dwarfing rootstocks (NRC 492, Taliparamba- 1) and one vigorous rootstock (Vengurla-4) of eight-years-oldcashew tree, as determined by the root excavation method. The root samples were collected vertically from different depths $(0-200 \mathrm{~cm})$ and laterally at different distances $(0-300 \mathrm{~cm})$ from the tree trunk. Results indicated that the root distribution pattern showed significant genotypic variation. Regarding the vertical distribution of roots, 95 percent of the roots were distributed in $0-100 \mathrm{~cm}$ horizons, while very few roots were in the 100-200 cm horizons. In the lateral distribution, 97 percent of root density was in the $0-200 \mathrm{~cm}$ area from the tree trunk. Vengurla4 (vigorous rootstock) had a higher root length, root volume and two-fold increases in total root production compared to dwarf rootstocks. PCA study revealed that the selection of rootstocks based on tree height, TCSA, canopy spread, lateral and vertical distribution of roots represent the main morphological indices for evaluating the effect of cashew rootstocks.
\end{abstract}

Keywords: Cashew, rootstocks, vertical distribution, lateral distribution, PCA

\section{Introduction}

Cashew (Anacardium occidentale L.), an evergreen tropical tree is adapted to the coastal areas of the western and eastern peninsular India. Presently, the cashew is grown in the country in an area of 10.62 lakh ha with the annual production of 8.17 lakh MT of raw nut and its average productivity of $753 \mathrm{~kg} \mathrm{ha}{ }^{-1}$. To meet the requirements of the processing industry, India imported 5.92 lakh MT of raw nuts valued at Rs 1811 Crores from African and Asian countries(Anon, 2019) ${ }^{[1]}$. Therefore, to ensure the steady supply of raw cashew nut domestically, it is important to increase the local production in India by adopting some important strategies such as quality planting material of improved/ high yielding varieties, high-density planting, integrated nutrient, pest and disease management to achieve the same. High Density Planting (HDP) is one of the improved productions technologies; it refers to the maximum utilization of available space by accommodating a greater number of trees per unit area for maximum production and productivity. Dwarf rootstocks are considered useful, economical and eco-friendly practices to control the vigour of tree in HDP system. Positive effect of rootstocks on scion-vigour management and productivity of HDP orchard was reported in several deciduous (apple, peach) and evergreen trees (mango, cashew, lemon, and pomegranate) (Webster, 1995) ${ }^{[16]}$. Root distribution patterns are considered essential to aid in the selection of rootstocks (Black et al., 2010) ${ }^{[3]}$. The root distribution pattern of trees varies from region to region and it is influenced by species, age of the tree, season, soil properties and other cultural practices (Singh et al., 2012) ${ }^{[12]}$. The structural relationship between the rootstock and scion shows the relationship between vigour reduction of rootstocks and dry matter content of the root (Bithell et al., 2016) ${ }^{[2]}$. Several previous reports are available to determine the cashew rooting pattern (Tsakiris and Northwood, 1967; Vidyadharan and Peethambaran, 1979; Harishu Kumar and Khader, 1985; Khader, 1986; Wahid et al., 1989, Salam et al., 1995 and Yadhukumar, 2001) ${ }^{[13,14,5,6,15,10,17]}$ but not to compare rootstocks. Earlier studies have shown that the root distribution pattern of cashew depends on the climate, planting material, tree age, type of soil and fertility, irrigation etc. (Kumar and Khader, 1985, Tsakiris and Northwood 1967, 
Vidyadharan and Peethambarm, 1979 and Yadhukumar, 2001) ${ }^{[8,13,14,17]}$. Precise information on root distribution in the rootstock decides the plant density, irrigation as well as to explore the possibility of using the subsoil resources of the soil and intercultural operations. However, root distribution pattern in cashew rootstocks is not well known under rain fed conditions. In this study, we examined the differences in root distribution patterns of cashew rootstocks and the relationships between scion vigour and yield.

\section{Materials and methods}

The present investigation was undertaken during the year 2016 in Experimental Station of Directorate of Cashew Research (DCR), Puttur, Dakshina Kannada District, Karnataka, India (latitude $12^{\circ} 46^{\prime} 36^{\prime \prime} \mathrm{N}$, longitude $75^{\circ} 16^{\prime} 08^{\prime \prime}$ and altitude72 $\mathrm{m}$ above MSL) in the soft wood grafted plants which were field planted in 2008 at a closer spacing of $6 \mathrm{~m} \mathrm{x}$ $6 \mathrm{~m}$ (278 trees/ha). Root excavation studies were carried out on eight year old cashew plants softwood grafted on rootstocks which comprised of dwarf types like NRC 492 and Taliparamba- 1 along with vigorous rootstock Vengurla-4.

\section{Root sampling}

Uniform and healthy trees were selected for excavation of roots on July-August, 2016; $3 \mathrm{~m}$ away from the trunk and all surface debris were removed. A hand-driven auger was used to collect the soil samples containing roots. The lateral distribution of roots was collected at $3 \mathrm{~m}$ from the trunk, using the excavation method. Lateral distribution was made up of intervals of $100 \mathrm{~cm}$, providing three sample portions of R1: 0$100 \mathrm{~cm}, \mathrm{R}_{2}: 100-200 \mathrm{~cm}$, and $\mathrm{R}_{3}: 200-300 \mathrm{~cm}$. Each portion was excavated for four depths viz., $\mathrm{D}_{1}$ : 0-50 cm, $\mathrm{D}_{2}$ : $50-100$ $\mathrm{cm}, \mathrm{D}_{3}: 100-150 \mathrm{~cm}$, and $\mathrm{D}_{4}: 150-200 \mathrm{~cm}$. Three trunk distances and four sampling depths and four directions provided forty-eight samples per tree (Fig.1). The roots from each block of soil were washed and dried in an oven at $70^{\circ} \mathrm{C}$ for 48 hours. Based on root diameter, the roots were classified into four size categories, such as feeder $(>0.2 \mathrm{~cm})$, thin $(0.2-$ $0.5 \mathrm{~cm})$, medium $(0.5-1.5 \mathrm{~cm})$ and thick $(<1.5 \mathrm{~cm})$. The density of roots spread laterally and vertically ware determined in terms of dry weight per soil volume and the same was calculated for the total root spread and depth of the tree. The mean root distributions between the rootstocks were compared by the chi-square test. The principal compound analysis (PCA) was done using the SAS statistical program (version 9.3) to determine the relationship between rootstock root distribution vs. vigour and yield of different stionic combinations.

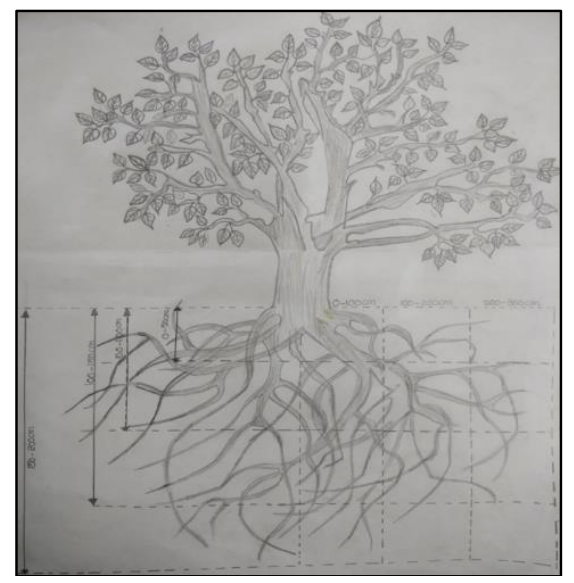

Fig 1: Root distribution Patten of cashew rootstocks

\section{Results and Discussion \\ Root distribution}

Root distribution at different distances from the tree trunk viz., $0-100 \mathrm{~cm}, 100-200 \mathrm{~cm}$ and $200-300 \mathrm{~cm}$ and soil depth is viz., $0-50 \mathrm{~cm}, 50-100 \mathrm{~cm} ; 100-150 \mathrm{~cm}$ and $150-200 \mathrm{~cm}$ revealed that 8 eight year old field planted cashew rootstocks had an extensive root system, spread over an area of $300 \mathrm{~cm}$ in lateral and $200 \mathrm{~cm}$ vertically from the soil surface (Fig 2 and Fig.3). The dry weight of roots of rootstocks ranged from $3.48 \mathrm{~kg}$ to $6.90 \mathrm{~kg} /$ trees.

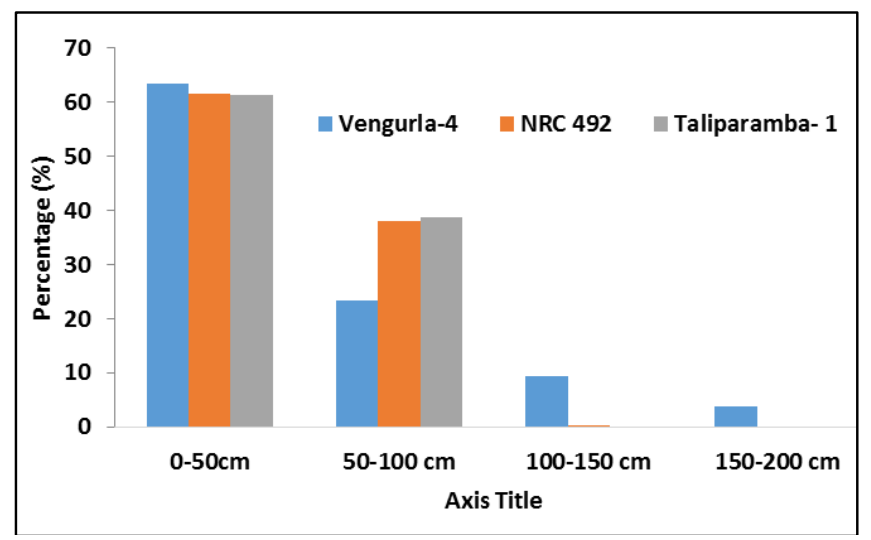

Fig 2: Effect of rootstocks on vertical distribution of roots

\section{Vertical distribution of roots}

Cashew rootstocks varied for the root penetration and distributions of the roots at different horizons of the soil profile. The roots of Vengurla-4 rootstock showed a uniform distribution of the root between the four horizons, 86.39 percent of roots found within horizons of $0-100 \mathrm{~cm}\left(\mathrm{D}_{1}\right.$ and $\mathrm{D}_{2}$ ), while 13.31 per cent of roots in 100 to $200 \mathrm{~cm}$ horizons $\left(D_{3}\right.$ and $\left.D_{4}\right)$, indicating a deep root architecture than NRC 492 and Taliparamba-1 (Fig. 2). Although Taliparamba-1 and NRC 492 were classified as dwarfing rootstocks, they had lower root penetration in the lower horizons $(100-200 \mathrm{~cm})$, with 99 per cent of roots in the $0-100 \mathrm{~cm}$ horizons $\left(\mathrm{D}_{1}\right.$ and $D_{2}$ ). The present study indicated that the maximum amount of root was found in the surface soil layer $\left(D_{1}: 0-50 \mathrm{~cm}\right.$ depth). This is in accordance with the findings of Salam et al. (1995) ${ }^{[10]}$, who reported about 89.3 per cent of roots of cashew in the surface horizon of $100 \mathrm{~cm}$. Tsakiris and Northwood (1967) ${ }^{[13]}$ reported that the $31 / 2$ years old cashew trees tap root extend to a depth of $2.3 \mathrm{~m}$ from ground surface. Khader (1986) ${ }^{[6]}$ studied the root distribution pattern of 10year cashew trees by soil excavation method and reported that 90 percent of cashew roots are found within $1 \mathrm{~m}$ depth and the maximum depth of roots extended was $9.5 \mathrm{~m}$. Apart from the (dwarf) nature of root stock, the soil texture also may play an important role in vertical distribution of roots (Vidyadharan and Peethambaran, 1979 and Harishukumar and Khader, $1985)^{[14,5]}$.

\section{Lateral distribution of roots:}

Overall, approximately $97 \%$ of lateral roots spread were recorded at $0-200 \mathrm{~cm}$ from the tree trunk. Vengurla-4 rootstock recorded a lateral spread of $200-300 \mathrm{~cm}\left(\mathrm{R}_{3}\right)$ from the trunk, but beyond this distance no roots were available. Whereas, Thalibaramba-1 recorded 94.25 per cent of the total roots within $100 \mathrm{~cm}$ radius $\left(\mathrm{R}_{1}\right)$ from the tree trunk and the remaining 5.75 per cent was occurred within a radius of 100$300 \mathrm{~cm}\left(\mathrm{R}_{2}\right.$ and $\left.\mathrm{R}_{3}\right)$ around the trunk. In NRC-492, 85 per cent of the total roots occurred at a distance of $0-100 \mathrm{~cm}\left(\mathrm{R}_{1}\right)$ from 
the trunk and the remaining 15 percent occurred in a radius of $100-200 \mathrm{~cm}\left(\mathrm{R}_{2}\right)$ around the trunk (Fig.3). The present study indicated that the maximum of roots was found in $100 \mathrm{~cm}\left(\mathrm{R}_{1}\right)$ radius from the tree trunk. Similar observations have been reported by Singh and Chandra (2009) ${ }^{[11]}$ in acid lime. Salam et al. (1995) ${ }^{[10]}$ reported a maximum root activity of 89.3 per cent at a depth of $100 \mathrm{~cm}$ vertically with a radius of $300 \mathrm{~cm}$ in 19-year-old cashew plantations raised from seedling. The lateral spread of the cashew roots varied with age of the tree (Tsakiris and Northwood, 1967) ${ }^{[13]}$, who found that the lateral spread of roots was up to $1.2 \mathrm{~m}$ in an 18 -month tree, $4.6 \mathrm{~m}$ in a $21 / 2$ years old tree and $5.6 \mathrm{~m}$ in 6 -year-old cashew trees.

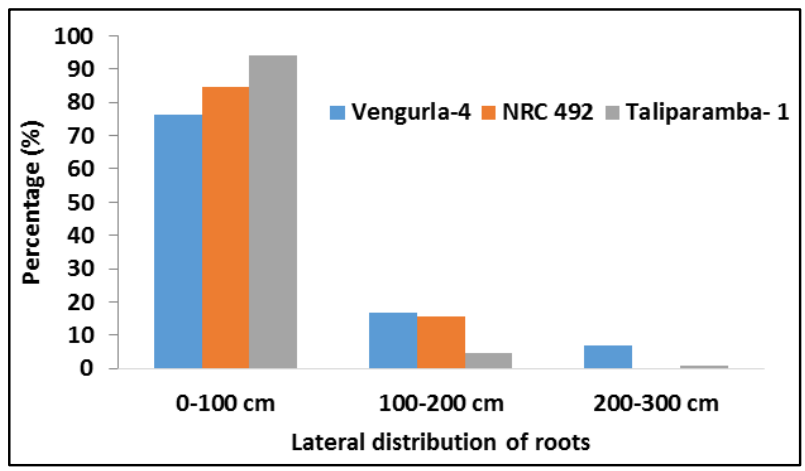

Fig 3: Effect of rootstocks on lateral distribution of roots

\section{Dry weight percentage of roots}

The vertical, lateral spread of roots was determined on dry weight basis and the results revealed that rootstock had a pronounced effect on the total dry weight of root (data not shown). The effect of rootstocks on dry root weight percentage is shown in Fig.4. The increases in depth of the roots between the rootstocks have been associated with concomitant increases in many feeder roots. However, the highest total dry root weight $(6.90 \mathrm{~kg})$ was associated with a deeper and more vigorous rootstock (Vengurla-4). The root systems of dwarf rootstocks were intermediate, but in most cases, they had some characteristics more similar to one or the other. The dwarf rootstock (NRC 492) had a deep but dense root system compared to Thalibaramba- 1 . The maximum dry weight of thick roots was observed between $0-100 \mathrm{~cm}$ from the trunk. Similar results were earlier reported in cashew by Tsakiris and Northwood (1967) ${ }^{[13]}$. The percentage of the total dry weight of the roots were found in the following order; thick roots $(54.10 \%)>$ thin roots $(15.66 \%)>$ medium roots $(14.81 \%)>$ feeder roots $(13.29 \%)$. Yadhukaumar (2001) ${ }^{[17]}$ reported 80 per cent of root activity in a radius of $1.2 \mathrm{~m}$ from the trunk with maximum fine roots (active roots$16.78 \%$ ) in a radius of $60-120 \mathrm{~cm}$ laterally under irrigated conditions in cashew. The root spread study conducted in the present trial indicated that vigorous rootstock (Vengurla-4) recorded higher root length, root volume and two-fold increases in the total root production compared to dwarf rootstocks. The study indicated that dwarf rootstocks can be utilized for propagating vigorous cultivars which are intended to be used for high density planting as dwarf rootstocks can reduce the spread of roots avoiding root completion under high density planting system. Further vigorous rootstocks should not be utilized when the intention is to go for high density planting.

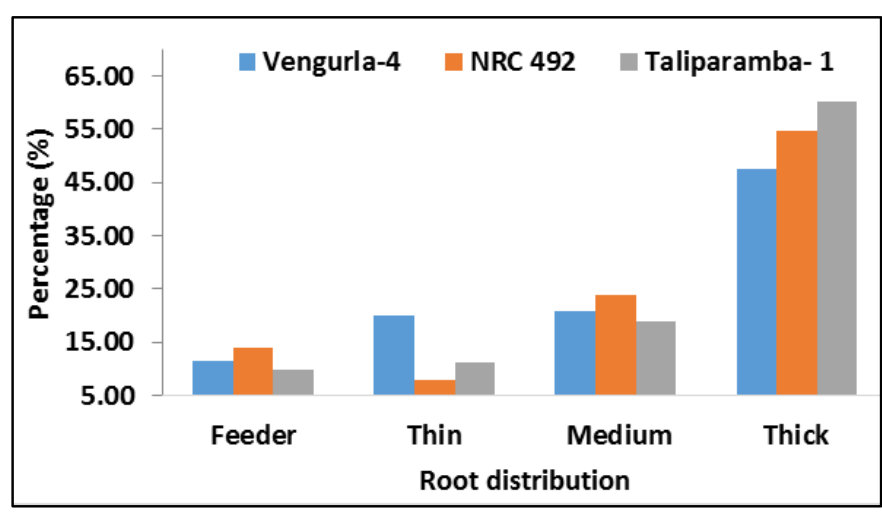

Fig 4: Effect of rootstocks on dry weight percentage of fibrous, thin, medium and thick roots

\section{Principal Component Analysis}

In the present investigation, various quantitative characteristics of cashew rootstocks were studied using PCA tool to find out the correlation coefficients of growth, yield, and root distribution characteristics. The results revealed that the canopy spread had a significant and positive correlation with scion growth (TCS A, tree height) and yield. At the same time, the vertical and lateral root distribution of rootstocks were negatively correlated to the canopy spread (Table 1) which means that the increase in yield is directly influenced by the increase in canopy spread, TCSA, tree height. TCSA and tree height had a positive correlation with the growth, root distribution, and yield of rootstocks, indicating a strong association of two characters. A similar positive correlation between TCSA for growth and yield was reported by Black et al. (2010) ${ }^{[3]}$ in cherry, Kumar et al. (2014) ${ }^{[7]}$ in apricot. Depth of rootstocks correlated to tree height; the taller tree has deep root system. Similar results were reported in citrus rootstock by Castle and Krezdron (1975) ${ }^{[4]}$. The cashew nut yield $\left(\mathrm{t} \mathrm{ha}^{-1}\right)$ was significantly and positively correlated with canopy spread, TCSA, tree height, lateral distribution of roots $(200-300 \mathrm{~cm})$, vertical distribution of roots $(100-200 \mathrm{~cm})$. In contrast, it was negatively correlated with the later distribution upto $0-200 \mathrm{~cm}$ and vertical distribution of roots upto $0-100 \mathrm{~cm}$. This indicates that these parameters did not contribute significantly to the yield. Therefore, the results showed that the selection of rootstock based on these traits can lead to higher yield per tree. These findings are close agreement with the findings of Salam et al. (1995) ${ }^{[10]}$ in cashew, Kumar et al. (2014) ${ }^{[7]}$ in apricot. Salam et al. (1995) ${ }^{[10]}$ found that the cashew tree develops an extensive root system and 89.3 percent of the roots occur $300 \mathrm{~cm}$ laterally and $100 \mathrm{~cm}$ vertically. The root density reduction concerning the lateral distance suggests that the fertilizer application should be done $300 \mathrm{~cm}$ laterally around the tree. However, Harishukumar and Khader (1985) [5] reported that the development of the cashew roots system mainly depends on soil texture. 
Table 1: Principal compound analysis (PCA) for the relationship between the cashew rootstocks on growth, yield and root distribution pattern

\begin{tabular}{|c|c|c|c|c|c|c|c|c|c|c|c|}
\hline & CS & LH & LTH & LTW & TCSA & TRHT & VF & VH & VOF & VTWH & YLD \\
\hline CS & 1.0000 & -.0816 & -.0840 & -.0744 & $\mathbf{0 . 8 8 3 7}$ & $\mathbf{0 . 8 8 6 9}$ & -.0824 & -.0110 & -.0851 & -.0847 & 0.4598 \\
\hline LH & & 1.0000 & 0.8925 & 0.9768 & 0.0863 & 0.1555 & 0.9994 & 0.4123 & 0.9315 & 0.9158 & -.1234 \\
\hline LTH & & & 1.0000 & 0.7751 & 0.0671 & 0.1244 & 0.9077 & -.0428 & 0.9954 & 0.9985 & 0.0725 \\
\hline LTW & & & & 1.0000 & 0.0890 & 0.1587 & 0.9687 & 0.5980 & 0.8319 & 0.8085 & -.2074 \\
\hline TCSA & & & & & 1.0000 & 0.8879 & 0.0855 & 0.0556 & 0.0724 & 0.0702 & 0.3328 \\
\hline TRHT & & & & & & 1.0000 & 0.1543 & 0.0931 & 0.1332 & 0.1296 & 0.3153 \\
\hline VF & & & & & & & 1.0000 & 0.3803 & 0.9436 & 0.9293 & -.1093 \\
\hline VH & & & & & & & & 1.0000 & 0.0526 & 0.0118 & -.4199 \\
\hline VOF & & & & & & & & & 1.0000 & 0.9992 & 0.0324 \\
\hline VTWH & & & & & & & & & 1.0000 & 0.0496 \\
\hline YLD & & & & & & & & & & & \\
\hline
\end{tabular}

Canopy spread, Lateral spread $(100 \mathrm{~cm})$, Lateral spread $(300 \mathrm{~cm})$, Lateral spread $(200 \mathrm{~cm})$, Trunk Cross-Sectional Area, Tree height, Vertical spread $(0-50 \mathrm{~cm})$, Vertical spread $(50-100 \mathrm{~cm})$, Vertical spread $(100-150 \mathrm{~cm})$, Vertical spread $(150-200 \mathrm{~cm})$, Yield $\left(\mathrm{t} \mathrm{ha}^{-1}\right)$

\section{Conclusions}

The root distribution pattern of vigorous/ dwarfing rootstocks of cashew examined in eight-year-old cashew plantation. The results indicated the potential benefits of dwarf rootstocks in view of reduced lateral spread and volume which could prevent the root competition under high-density planting systems. This would make the high-density planting system a sustainable option. The principal compound analysis revealed that the selection of rootstocks based on tree height, TCSA, canopy spread, lateral and vertical distribution of roots represents the main morphological indices to evaluate the effect of cashew rootstocks.

\section{Acknowledgments}

We would like to thank the ICAR- Directorate of Cashew Research, Puttur, Karnataka, India for their financial support.

\section{References}

1. Anonymous, 2019. Area and production of cashew 201718 in India. Directorate of Cashew nut and Cocoa Development (DCCD), Kochi, Kerala. https://dccd.gov.in Accessed 05 January, 2019.

2. Bithell SL, Tran-Nguyen LTT, Hearnden MN, Hoult MD, Hartley N, Smith MW. Fine root dry matter relative to mango (Mangifera indica) tree scion size grafted on size-controlling rootstocks, is negatively related to scion growth rate. Trees, 2016; 30:1181-1190. https://doi.org/10.1007/s00468-016-1355-Z

3. Black Bl, Dan Drost, Thor Lindstrom, Jennifer Reeve, JayDee Gunnell a, Gregory LRA. Comparison of Root Distribution Patterns Among Prunus Rootstocks. Journal of the American Pomological Society. 2010; 64(1):52-62.

4. Castle WS, Krezdorn AH. Effect of citrus rootstocks on root distribution and leaf mineral content of Orlando Tangelo trees. Journal of American Society for Horticultural Science. 1975; 100:1-4.

5. Harishukumar P, Khader KBA. Root proliferation in cashew seedlings as influenced by soil texture. Indian Cashew J. 1985; 15(2):7-14

6. Khader KBA. Distribution of cashew in the laterite soil of west coast of India. Cashew J. 1986; 15(2):15-19

7. Kumar D, Ahmed N, Srivastava KK, Dar TA. Effect of trunk cross sectional area of rootstock on growth, yield, quality and leaf nutrient status in apricot (Prunus armeniaca) cv CITH-Apricot-2. Indian Journal of Agricultural Sciences. 2014; 84(2):236-40.

8. Kumar HP, Khader KBA. Root proliferation in cashew seedling as in influenced by soil texture. Indian cashew Journal.1984; 15(2):7-14

9. Misra KK, Singh R, Singh AK, Singh R, Rai D, Jaiswal HR et al. Studies on root distribution pattern of lemon
(Citrus limon Burm.) on Poncirus trifoliata rootstock. Progressive Horticulture. 1999; 31:101-104

10. Salam AM, Pushpalatha PB, Suma A. Root distribution pattern of seedling raised cashew trees. $\mathrm{J}$ of plantation crops. 1995; 23(1):59-61

11. Singh B, Chandra A. Studies on rooting pattern of acid lime by root excavation. Annals of Agriculture Research. 2009; 30:13

12. Singh N, Prasad VM, Bangari B, Uniyal S, Misra KK. Studies on the effect of season, radial distances and depth on root distribution in guava cv. Allahabad Safeda. Indian Journal of Horticulture, 2012; 69(4):495-500.

13. Tsakiris A, Northwood PJ. Cashew nut production in southern Tanzania IV. The root system of cashew nut tree. East Africa forestry J. 1967; 33(1):83-87

14. Vidyadharan KK, Peethambaran CK. Root studies in cashew air layers and seedlings. In. cashew research and development (Eds.) E.V.V.Bhaskara Rao and H. Hameed Khan, Indian society for plantation crops, Kasaragod, 1979, 296.

15. Wahid PA, Kamalam NV, Asokan PK, Vidyadharan KK. Rooty activity pattern of cashew. J. of plantation crops.1989; 17(2):85-89.

16. Webster D. Rootstock and interstock effects on deciduous fruit tree vigour, precocity, and yield productivity, New Zealand Journal of Crop and Horticultural Science. 1995; 23(4):373-382.

17. Yadhukumar N. Efficacy of drip irrigation and graded nitrogen phosphorous and potassium on the productivity of cashew. Ph.D. Thesis. Submitted to Mangalore University, 2001. 